\title{
AN ANALYSIS OF INTER-BAR CURRENTS ON A POLYPHASE CAGE INDUCTION MOTOR
}

\author{
Renato Carlson $^{1} \quad$ Cláudia A. da Silva $^{1} \quad$ Nelson Sadowski $^{1} \quad$ Michel Lajoie-Mazenc $^{2}$ \\ ${ }^{1}$ GRUCAD/CTC/UFSC- Campus Universitário - Florianopolis - SC - 88040-900 - BRAZIL \\ ${ }^{2}$ LEEI/ENSEEIHT/INPT UMR CNRS 5828 - 2 rue Camichel- 31071 - Toulouse - FRANCE
}

\begin{abstract}
This work uses a methodology based on 2D-Finite Element Method (FEM) and on the Circuits Theory (Independent Currents Method) to analyze the inter-bar currents on the rotor of cage induction motors. The Multi-Slice Technique is used to consider the skewing effect. Three conditions are considered: one inter-bar resistance, two inter-bar resistances and three inter-bar resistances. The results show the distribution of currents in the rotor bars, short-circuit rings and transversal resistances at a given time. The fundamental component of the inter-bar and surrounding bar currents are shown to help understanding the phenomenon.
\end{abstract}

KEYWORDS: induction motor, inter-bar, stray load losses, cage rotor.

\section{RESUMO}

Este trabalho usa uma metodologia baseada no Método de Elementos Finitos 2D (FEM) e na Teoria de Circuitos (Método das Correntes Independentes) para analizar as correntes inter-barras no rotor de um motor de indução com rotor de gaiola. A Técnica de Multiplas Fatias é usada para considerar o efeito da inclinação das barras do rotor. Três condições são consideradas: uma resistência inter-barra, duas resistências inter-barras e três resistências inter-barras. Os resultados mostram a distribuição das correntes nas barras do rotor, anéis de curto-circuito e resistências

\footnotetext{
Artigo Submetido em 08/01/04

1a. Revisão em 13/04/04;

Aceito sob recomendação do Editor Associado

Prof. Dr. Prof. José Antenor Pomilio
}

transversais em dado momento de tempo. A componente fundamental da corrente nas resistências inter-barras e nas barras circundantes é mostrada para auxiliar na compreensão do fenômeno.

PALAVRAS-CHAVE: motor de indução, interbarra, perdas adicionais em carga, rotor em gaiola.

\section{INTRODUCTION}

Inter-bar currents have been investigated in the last few years because they are one important component of the stray load losses in cage induction motors. According to C.N. Glew (1997), even in the present day, the stray load losses are a challenge to the industrial and scientific community because there is not consensus on standard methods to measure and calculate them.

The inter-bar currents, related to the rotor bar insulation problems, produce the inter-bar losses that can represent one-third of the total stray load losses. To reduce the interbar losses represents to increase the efficiency of the motor and industrial experiences confirm the better performance of induction motors with insulated rotor bars.

Important contributions are found in the literature about the inter-bar currents problem. The analytical work of Odok (1958) and Rao and Butler (1969) were the main reference for several decades. Recently, Williamson and Boger (1999) have studied the effect of the inter-bar currents in a Brushless Doubly Fed Motor. The 2D and 3D-Finite Element Methods are used by Ho et al. (1998)(1999) to estimate the inter-bar losses of an induction motor.

The effect of the skewing on the inter-bar currents is shown by Odok (1958) and Rao (1969) using an analytical method and by da Silva et all (2000) using a numerical method. In 
agreement with da Silva et all (2000), for skewed motors with very low end-ring impedance, only the effective rotor bar insulation can avoid the inter-bar currents and consequently the inter-bar losses.

In this work a methodology based on the 2D-Finite Element Method and the Circuits Theory (Independent Currents Method) is used to analyze the inter-bar currents on a Polyphase Cage Induction Motor, specially the influence of the position of the transversal resistance in the rotor circuit on these currents.

The rotor end-ring impedance and skin effect are taken into account. The skew effects are considered by using MultiSlice Technique (an approach to represent the skewing in two dimensions). The effect of the amature windings end turns is neglected.

\section{NUMERICAL MODEL(da Silva et alii 2000)}

By using the multi-slice technique the structure is divided in $n f t$ slices and the angle difference between slices is $\alpha$ which is defined by the skew angle $\delta$ and $n f t$.

From the Maxwell's equations and introducing the magnetic vector potential $A$ and the scalar potential $\phi$ we obtain in each slice the partial differential equations given by (1) to each slice $s$ as given in (1). The cuts in the structure are symmetrical and the length of each slice is $1_{x}$. The coefficients $v$ and $\sigma$ are the magnetic reluctivity and the electric conductivity respectively [9].

$$
\begin{aligned}
& \nabla \times\left(v \nabla \times A^{s}\right)-\sigma \frac{\partial A^{s}}{\partial t}+\frac{N_{c o}}{S_{b}} I_{b}{ }^{s}+\frac{\sigma}{l_{x}} U_{c}^{s}=0 \\
& R_{b}^{s} I_{b}{ }^{s}+\frac{l_{x} N_{c o}}{\mathbf{S}_{\mathbf{b}}} \iint_{S_{b}} \frac{\partial A^{s}}{\partial t} d S-U_{b}{ }^{s}=0 \\
& R_{c}^{s} I_{c}{ }^{s}+R_{c}^{s} \sigma \iint_{S_{c}} \frac{\partial A^{s}}{\partial t} d S-U_{c}{ }^{s}=0
\end{aligned}
$$

The number of turns in series in each coil of the stator winding is $N_{c o}$. The current, cross section and d.c. resistance of each slice of this coil are $I_{b}, S_{b}$ and $R_{b}$ respectively. $U_{c}$, $R_{c}$ and $S_{c}$ are the voltage drop, resistance and cross section of each slice of the massive conductor.

The electromagnetic torque is calculated using the Maxwell Stress.

\subsection{Rotor circuit equations with inter-bar resistance}

Transversal resistances $r_{q}$ are inserted between the rotor bars as shown in Fig.1 where the Finite Elements Method models the $\mathrm{ncm}$ rotor bars.

By using the Circuits Theory (Independent Current Method) one tree with $n$ edges is selected where the loops of this tree are defined as the $\mathrm{ncm}$ inferior ring segments, the inter-bar resistances and the last superior ring segments. The tree branches are the ( $n \mathrm{~cm} \times \mathrm{nft}$ ) bar segments and the $(n c m-1)$ superior ring segments. The tree selected is shown in Fig. 1 where the heavy lines represent the branches and the thin lines represent the loops. $Z_{r}$ is the end ring segment impedance and $U_{c i, j}$ is the voltage of each bar segment modeled by Finite Elements.

Satisfying the Kirchoff's Laws, two equations are obtained from the rotor circuit of the Fig.1. According to Boite, R. and Neirynck, J. (1996), the first equation, shown in (3) respects the relation between the loop currents and branch currents. The second one, shown in (4) respects the relation between the loop voltages and branch voltages.

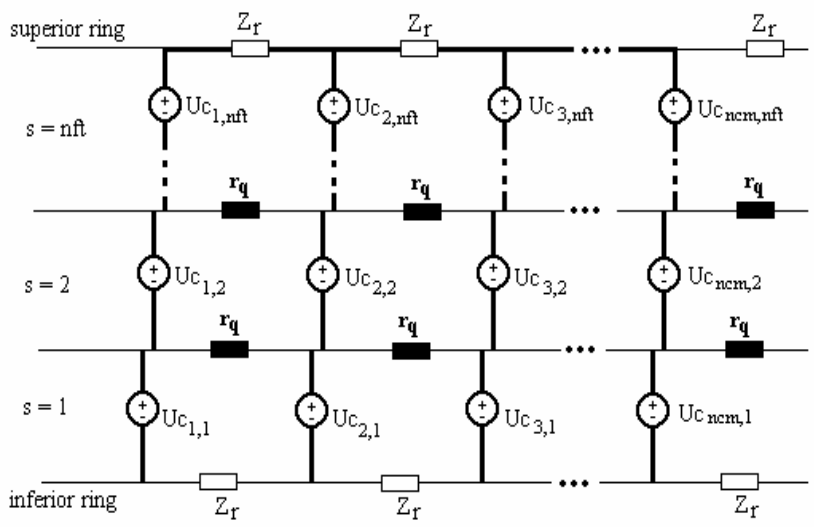

Figure 1- Rotor circuit with selected tree Heavy lines : branches; Thin lines : loops

$$
\begin{gathered}
I_{C}-B_{1 a} I_{m}=0 \\
B_{1 a}{ }^{T} U_{C}+R_{M} I_{m}+L_{M} \frac{d}{d t} I_{m}=0
\end{gathered}
$$

Matrix $B_{l a}{ }^{T}$ is taken from the Fundamental Mesh Matrix that is obtained directly by the number of the rotor bars and slices defined to skew the rotor.

Vector $U_{C}$ and $I_{C}$ contains the voltage drop and currents of all rotor bar segments respectively. $R_{M}$ and $L_{M}$ are the resistance and matrix inductance associated to the tree. The inter-bar resistance $\mathrm{r}_{\mathrm{q}}$ is taken into account in the $R_{M}$ matrix and it can be assumed the same or not in the matrix system. 


\subsection{Coupling the equations}

Equations (2) and (3) associated to the tree are coupled to the field equations of (1). The continuity of the stator current is imposed then $\mathrm{I}_{\mathrm{b}}{ }^{1}=\mathrm{I}_{\mathrm{b}}{ }^{2}=\ldots=\mathrm{I}_{\mathrm{b}}{ }^{\mathrm{nft}}$. The continuity of the rotor bar currents $\left(\mathrm{I}_{\mathrm{c}}{ }^{1}=\mathrm{I}_{\mathrm{c}}{ }^{2}=\ldots=\mathrm{I}_{\mathrm{c}}{ }^{\mathrm{nft}}\right)$ is also imposed when the transversal resistance is not introduced.

The coupled equations to all slices are solved simultaneously step-by-step by using the Euler Method and can be written in the matrix form of (4). This model is solved at first to give an initial estimated value of $A(0)$, $I_{B}(0), U_{C}(0), I_{C}(0), I_{m}(0)$ and after the system of large equations is solved at each time using the result of last step. The vector $U_{B}$ is the source vector.

The inter-bar currents are taken directly from the vector $I_{m}$ defined as the vector that contains all inferior ring segments currents, the inter-bar currents and the last superior ring segment current.

By this way if one or more inter-bar resistances are inserted in the rotor circuit it is possible to know the current associated to it and to verify its influence in the others parameters of the machine.

$$
\begin{aligned}
& {\left[\begin{array}{lllll}
\mathrm{M}_{1} & \mathrm{M}_{2} & \mathrm{M}_{3} & 0 & 0 \\
\mathrm{M}_{4} & \mathrm{M}_{5} & 0 & 0 & 0 \\
\mathrm{M}_{6} & 0 & \mathrm{M}_{7} & \mathrm{M}_{8} & 0 \\
0 & 0 & \mathrm{M}_{9} & 0 & \mathrm{M}_{10} \\
0 & 0 & 0 & \mathrm{M}_{11} & \mathrm{M}_{12}
\end{array}\right]\left[\begin{array}{l}
\mathrm{A}(\mathrm{t}) \\
\mathrm{I}_{\mathrm{B}}(\mathrm{t}) \\
U_{C}(\mathrm{t}) \\
I_{C}(\mathrm{t}) \\
I_{m}(\mathrm{t})
\end{array}\right]=} \\
& {\left[\begin{array}{ccccc}
\mathrm{M}_{13} & 0 & 0 & 0 & 0 \\
\mathrm{M}_{14} & \mathrm{M}_{15} & 0 & 0 & 0 \\
\mathrm{M}_{16} & 0 & 0 & 0 & 0 \\
0 & 0 & 0 & 0 & \mathrm{M}_{17} \\
0 & 0 & 0 & 0 & 0
\end{array}\right]\left[\begin{array}{l}
\mathrm{A}(\mathrm{t}-\Delta \mathrm{t}) \\
\mathrm{I}_{\mathrm{B}}(\mathrm{t}-\Delta \mathrm{t}) \\
U_{C}(\mathrm{t}-\Delta \mathrm{t}) \\
I_{C}(\mathrm{t}-\Delta \mathrm{t}) \\
I_{m}(\mathrm{t}-\Delta \mathrm{t})
\end{array}\right]+\left[\begin{array}{l}
0 \\
U_{B}(t) \\
0 \\
0 \\
0
\end{array}\right]}
\end{aligned}
$$

\section{MODEL VALIDATION}

The developed numerical model is applied to analyze a three phase induction motor rated $1000 \mathrm{~kW}, 8$ poles, $60 \mathrm{~Hz}$, 6000 Volts with skewed and non skewed rotor slots. This motor has 18 slots per pole in the stator and 22 slots per pole in the rotor. The skewing angle of the rotor slots in the skewed motor is about $1 / 4$ stator slot pitch.

Figure 2 shows a picture of the skewed rotor where the effect of inter-bar currents is observed close to the ventilation holes. A closer view of the rotor is shown in Fig. 3 where the damage due to the inter-bars currents is more pronounced.

In order to validate the numerical model, the only available experimental data corresponds to the rated armature currents. For the non-skewed motor the measured rms value of the armature current was $117.34 \mathrm{~A}$ while the corresponding value obtained by simulation at rated slip was 117.24A. For the skewed motor the measured rms value of the armature current was $120.5 \mathrm{~A}$ while the corresponding value obtained by simulation at rated slip was 118A. The good agreement between measured and simulated values allows validating the numerical model.

The results presented in the next sections of the paper were obtained resolving the above finite elements model until the rotor quantities attain the steady-state. In order to make the calculation time reasonable enough for obtaining all the results we needed, we decided to make all the following calculations for a slip of about $10 \%$ and not for the nominal one. This fact does not invalidate the results and conclusions. Each finite elements resolution of this model for this slip took about 6 hours in a Pentium $41.0 \mathrm{GHz}$ PC microcomputer.

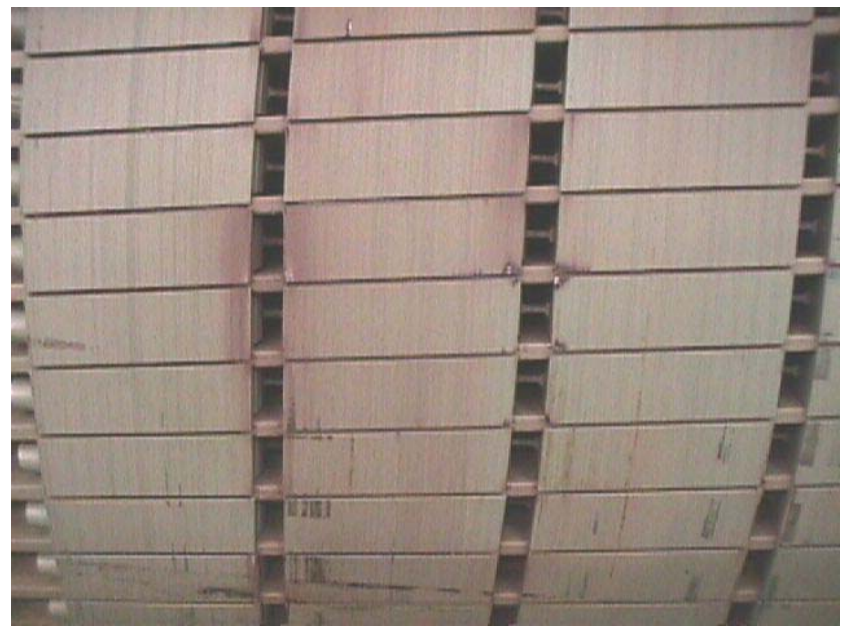

Figure 2 - Skewed rotor view.

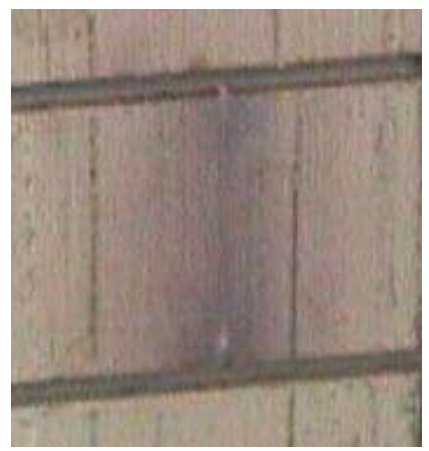

Figure 3 - Rotor view with damaged area.

A view of the transversal section of the motor can be seen in Fig. 4 where the flux lines are drawn. 


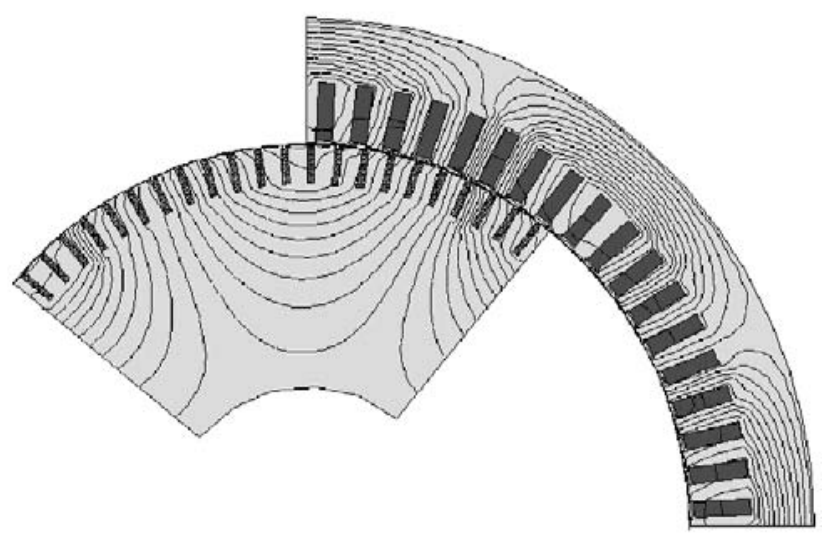

Figure 4 - Flux lines over one pole pair of the motor.

\section{THE EFFECT OF SKEWING THE ROTOR BARS}

The first simulation results present a comparison of the current waveform and harmonic content of the armature current for the non-skewed rotor as well as for the skewed rotor. For this last case the rotor bars were considered skewed 5 mechanical degrees, which correspond to one stator slot pitch and not only 1.25 mechanical degrees as it is in the real motor. This was done in order to put into evidence the effect of skewing the rotor bars.

Fig. 5 and Fig. 6 show the effect of skewing over the armature current. In particular, its effect is mostly apparent over the $21^{\text {st }}$ harmonic which corresponds to the main rotor slot harmonic. It is important to observe that this motor has by its design a low level of slot harmonics, for that reason it was designed originally with the rotor bars skewed $1 / 4$ of the stator slot pitch.

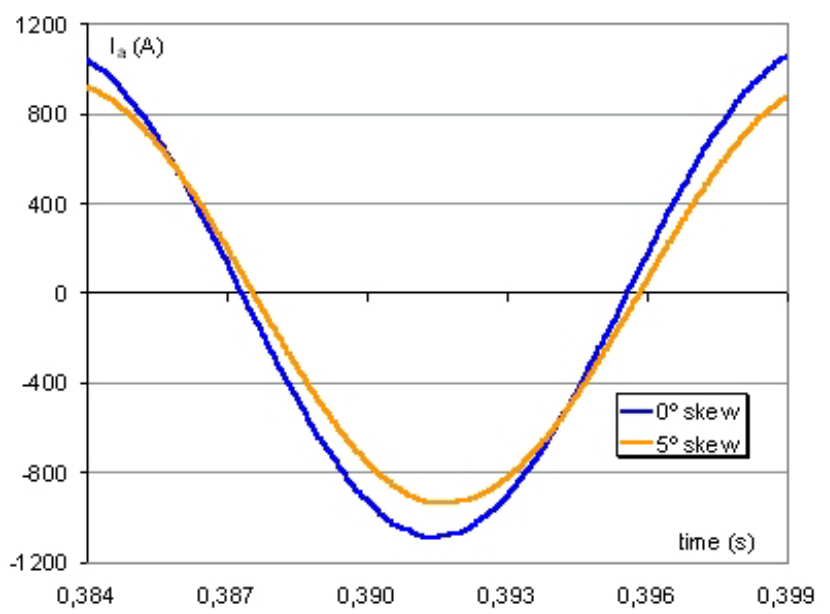

Figure 5 - Armature current with no skew and 1 stator slot pitch skewing angle.

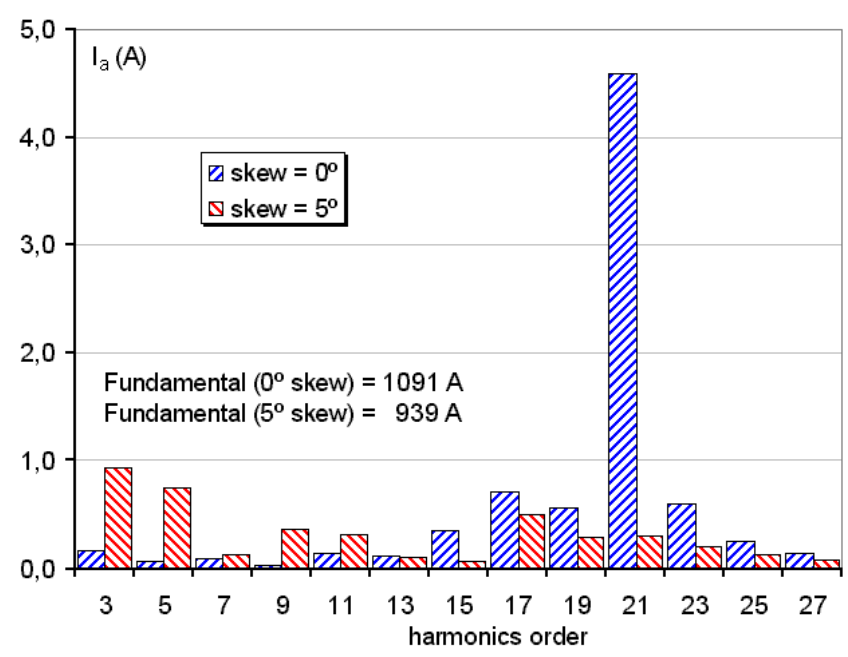

Figure 6 - Harmonics of the armature current with and without skewing.

\section{ANALYSIS OF THE INTER-BAR CURRENTS}

It is almost impossible to obtain experimentally the value of the inter-bar resistances because their magnitudes are very low, in the order of the measuring instruments precision. Due to this an arbitrary value of $40 \mu \Omega$ was adopted.

To study the inter-bar currents in the rotor of a skewed induction motor 4 slices where adopted to represent the skewing. The numerical model presented in section 2 permits to represent any number of inter-bar resistances. Fig. 7 show the grid formed by the bar segments and the inter-bar resistances inserted and the notation used hereafter to designate the inter-bar resistances and the bar segments.

The analytical work of Odok, A. (1958) shows that if the end-ring impedance is negligible, the bar current of a non-

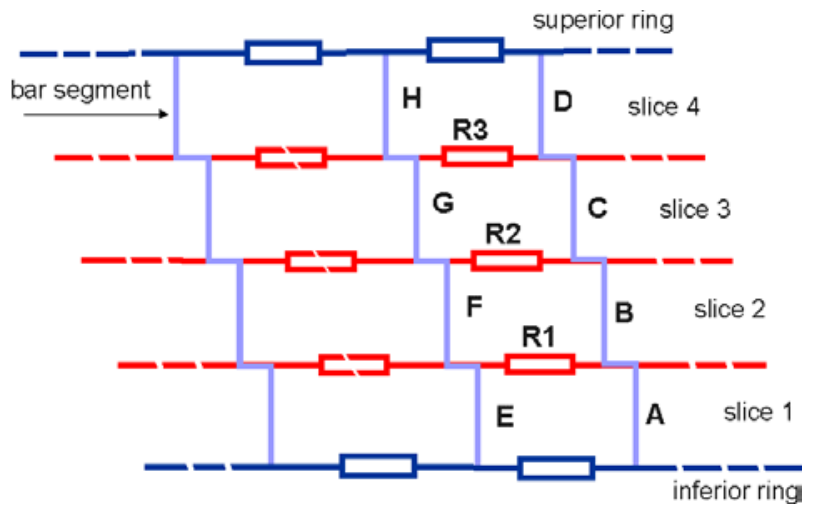

Figure 7 - Grid formed by the bar segments and the interbar resistances inserted and the respective notation. 
skewed motor is constant over the length of the bar and there are no inter-bar currents flowing in the rotor circuit, even if there are transversal resistances between bars.

A simulation without skewing the rotor but considering the three inter-bar resistances of Fig. 7 permits to verify this condition. For the simulation the resistance of the ring segments between two bars was $1 \mu \Omega$ low enough but not negligible. Fig. 8 shows the current distribution in the rotor for a given instant of time.

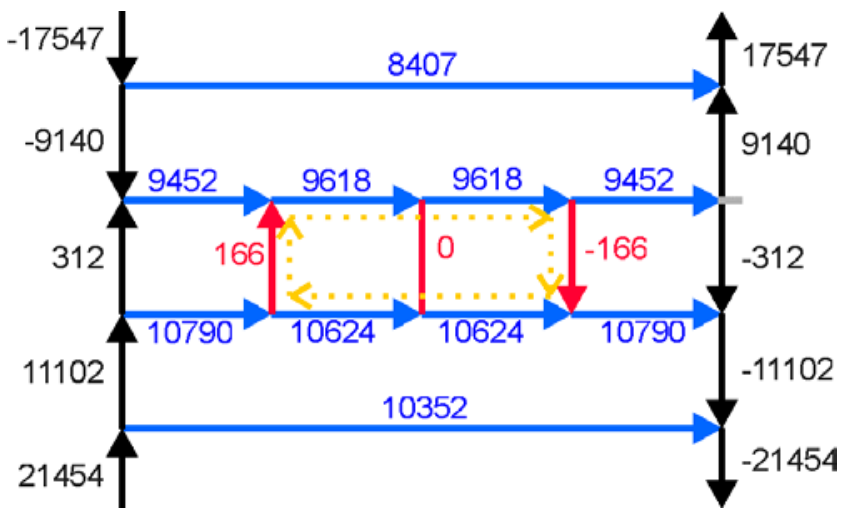

Figure 8 - Current distribution in the rotor grid at a given time with three transversal resistances and no skew.

A small amount of inter-bar current is flowing through R1 and R3. The path of this current is indicated in Fig. 8 by the dotted line. The rotor is symmetric in the axial direction as can be seen in this figure and that is why the current in R2 is zero. Fig. 9 shows the inter-bar currents as a function of time.

Three cases where studied next with the rotor bars skewed $5^{\circ}$. The first one with only one transversal resistance inserted and designated as R1 in Fig. 7. The second one with two resistances inserted and designated as R1 and R2. The last one considered three resistances inserted and designated as R1, R2 and R3.

Initially, the distribution of the currents at a given instant of time over the portion of the rotor grid presented in Fig. 7 without any inter-bar resistance is shown in Fig. 10. The values of current shown in this figure will serve as a reference for the three cases to be analyzed.

\subsection{One inter-bar resistance (R1)}

Fig. 11 shows a portion of the rotor grid for the case where there is only one inter-bar resistance. The arrows indicate the direction of the currents at a given instant of time in the bar segments, in the ring segments and in the transversal resistance R1. The path of the current due to the presence of the inter-bar resistance is indicated in this figure by a dashed line and show that the inter-bar current flows from one bar segment to the next one in the direction of the rotor bar skewing.

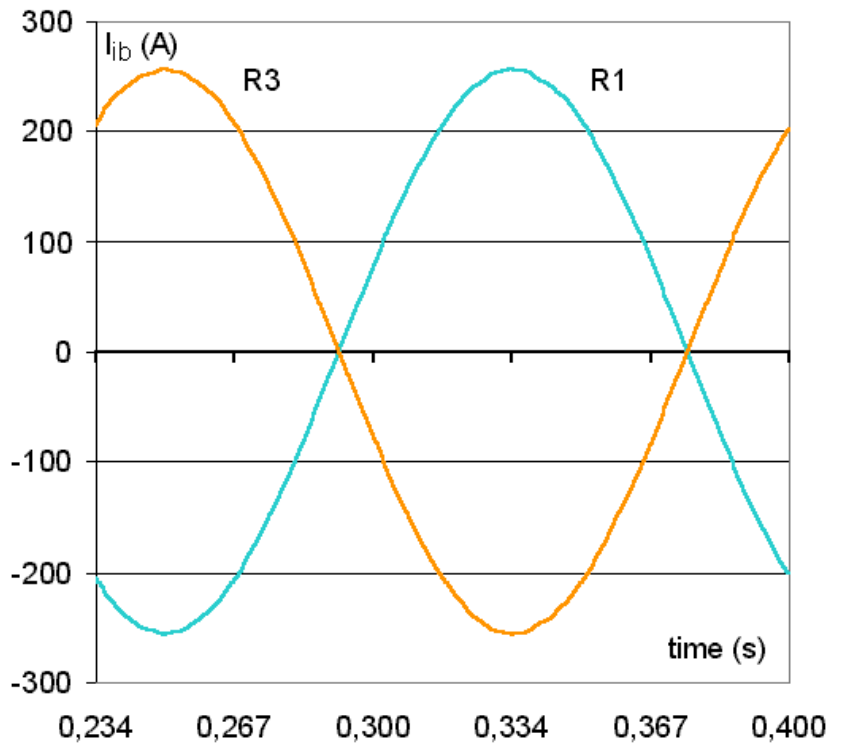

Figure 9 - Inter-bar currents without skewing.

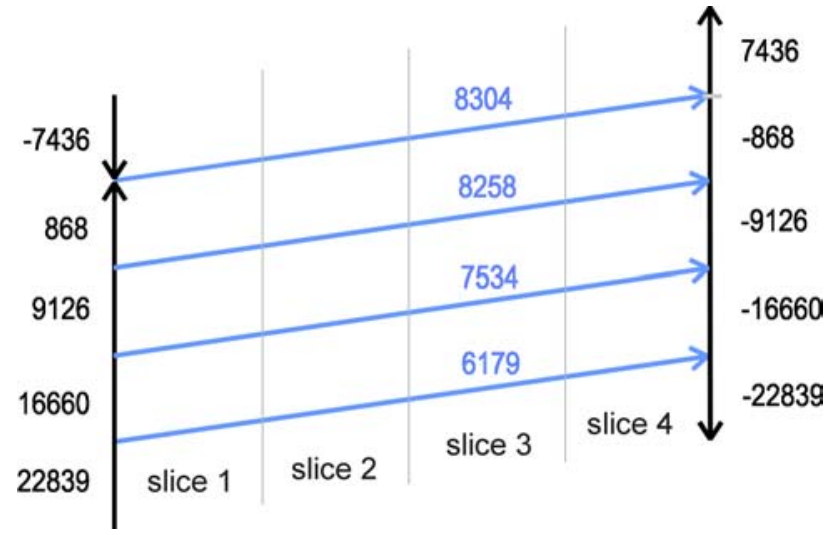

Figure 10 - Current distribution in the rotor grid at a given time without any transversal resistance.

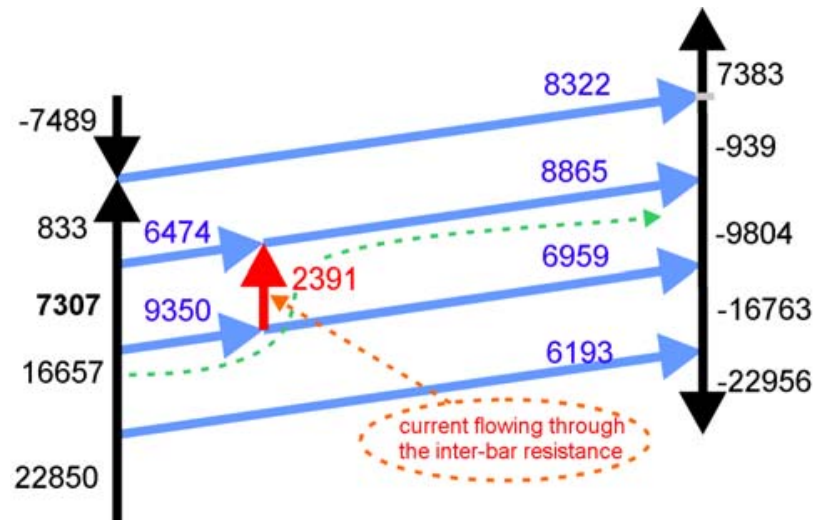

Figure 11 - Current distribution in the rotor grid at a given time with one transversal resistance and with $5^{\circ}$ skewing. 
The fundamental components of the currents in the bar segments surrounding the transversal resistance are shown in Fig. 12. The amplitude of the fundamental component of the inter-bar current is, in this case, $2822 \mathrm{~A}$. This figure shows that only the bar segments A and B currents are affected by the presence of the inter-bar resistance $\mathrm{R} 1$. Also, the current in bar segment $\mathrm{A}$ is increased by the amount of inter-bar current while the current in segment $\mathrm{E}$ is decreased of the same amount confirming the previous conclusion.

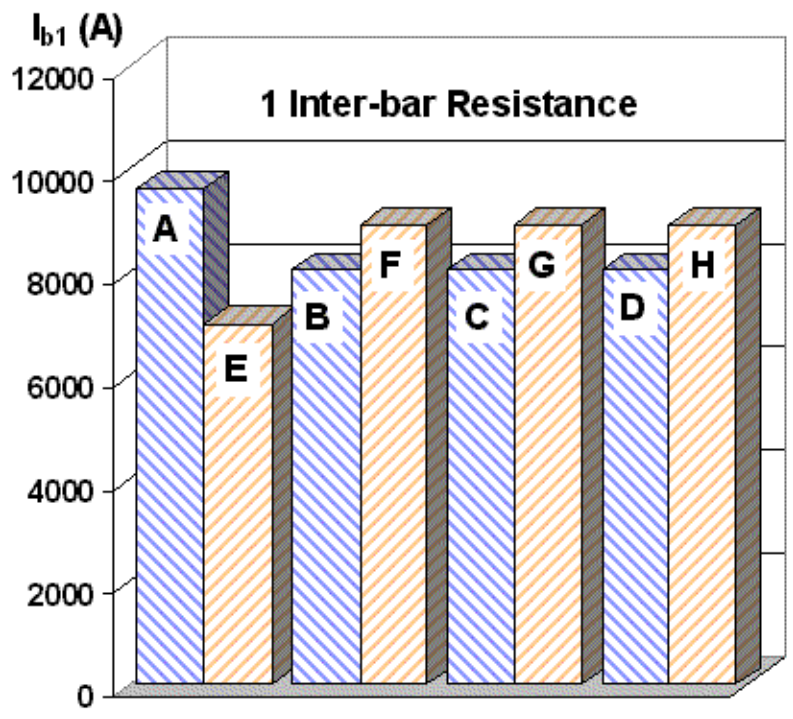

Figure 12 - Amplitude of the fundamental component of the bar currents surrounding inter-bar resistance R1 (refer to Fig. 7 for notation).

The waveform of the inter-bar current flowing through resistance R1 is shown in Fig. 13 and its harmonic spectrum is shown in Fig. 14.

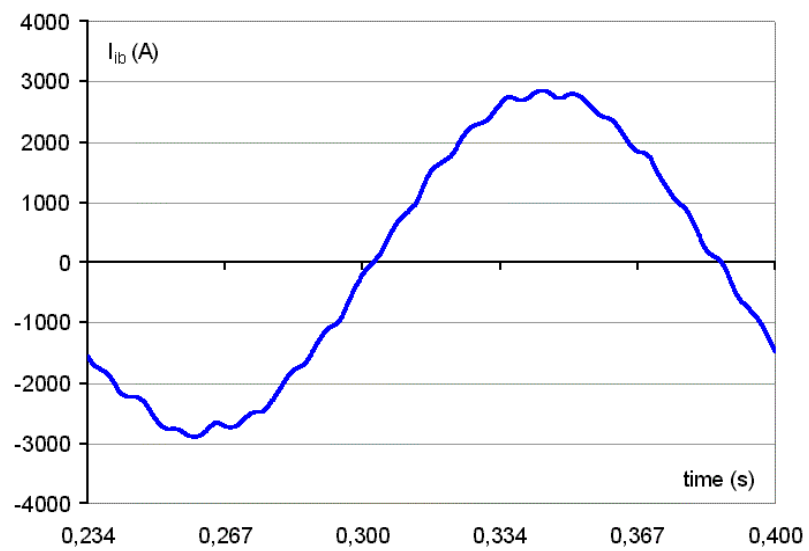

Figure 13 - Waveform of the current flowing through interbar resistance R1.
These figures show that the main harmonic of the inter-bar current corresponds to the stator main slot harmonic, i.e. the $19^{\text {th }}$. It is interesting to note that the predominant harmonic in the armature current is the $21^{\text {st }}$ that corresponds to the rotor slot harmonic. The amplitude of the $19^{\text {th }}$ harmonic of the inter-bar current corresponds to $2.25 \%$ of the amplitude of its fundamental. Besides the fundamental component and the $21^{\text {st }}$ harmonic there is also a significant ninth harmonic of about $30 \mathrm{~A}$ peak value. This ninth harmonic corresponds to the $60 \mathrm{~Hz}$ frequency of the armature currents. All other harmonics are not significant.

\subsection{Two inter-bar resistances ( $R 1$ and R2)}

Fig. 15 shows the same portion of the rotor grid as in Fig. 11 , but this time for the case where there are two inter-bar resistances. The arrows indicate the direction of the currents at a given instant of time in the bar segments, in the ring segments and in the transversal resistances $\mathrm{R} 1$ and R2. The path of the currents due to the presence of the inter-bar resistances are indicated in this figure by two dashed lines that show the same effect of displacement of the currents in the direction of the rotor bar skewing.

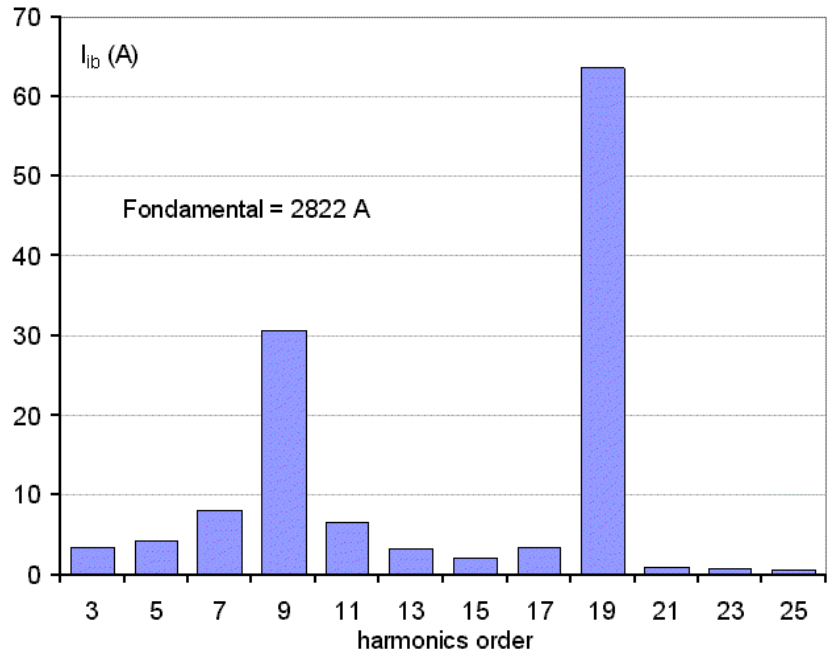

Figure 14 - Fourier series decomposition of the current flowing through the inter-bar resistance R1. 


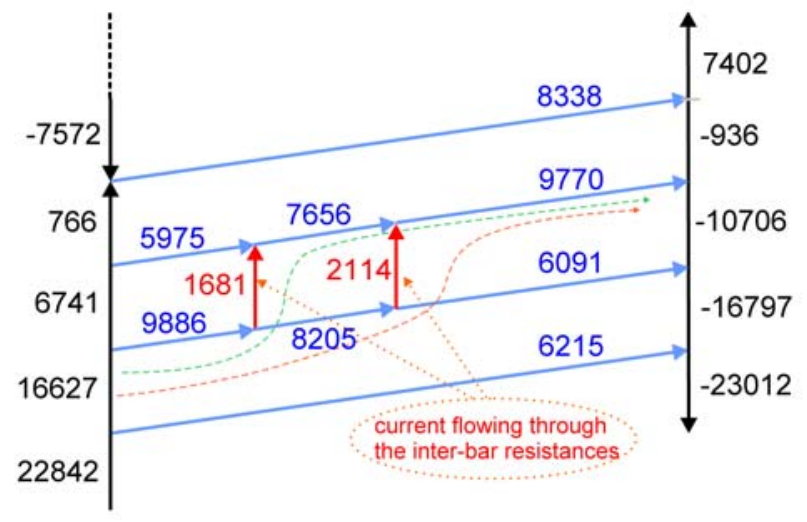

Figure 15 - Current distribution in the rotor grid at a given time with two transversal resistances.

The fundamental components of the currents in the bar segments surrounding the transversal resistances are shown in Fig. 16. The amplitude of the fundamental component of the inter-bar currents is, in this case, $1801 \mathrm{~A}$ in R1 and $2288 \mathrm{~A}$ in $\mathrm{R} 2$. This figure shows now that the current in bar segments A, B, E and F currents are affected by the presence of the inter-bar resistances R1 and R2. Also, the currents in bar segments A and B are increased while the currents in segments $\mathrm{E}$ and $\mathrm{F}$ are decreased confirming the previous conclusion.

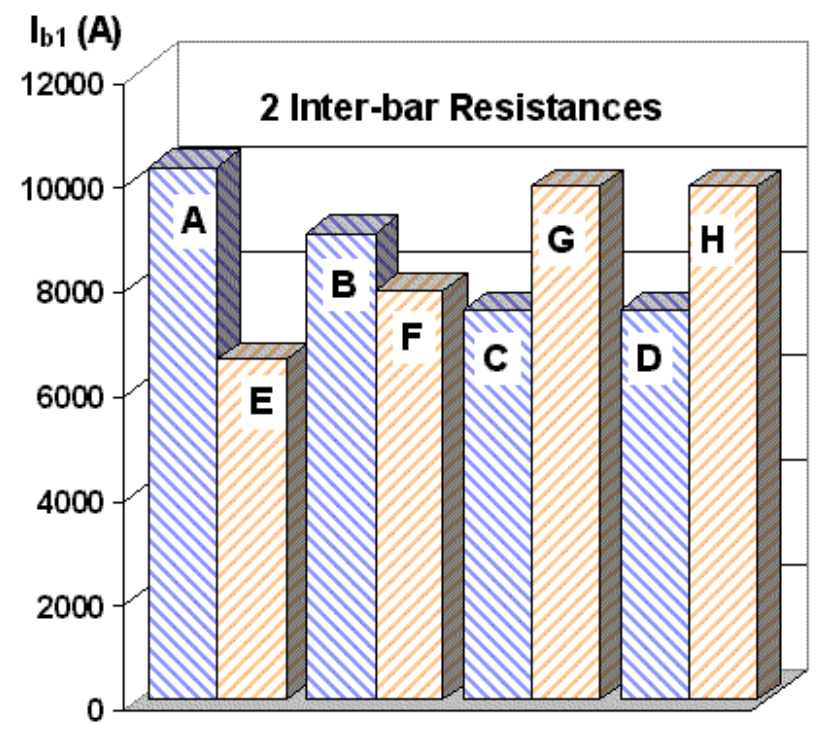

Figure 16 - Amplitude of the fundamental component of the bar currents surrounding inter-bar resistances R1 and R2 (refer to Fig. 7 for notation).

\subsection{Three inter-bar resistances ( $\mathbf{R} 1, \mathbf{R} 2$ and R3)}

Fig. 17 shows the same portion of the rotor grid as in Fig. 11 and Fig. 15, but this time for the case where there are three inter-bar resistances. The arrows indicate the direction of the currents at a given instant of time in the bar segments, in the ring segments and in the transversal resistances R1, R2 and R3. The path of the currents due to the presence of the inter-bar resistances are not indicated in this figure but the same effect of displacement of the currents in the direction of the rotor bar skewing is observed.

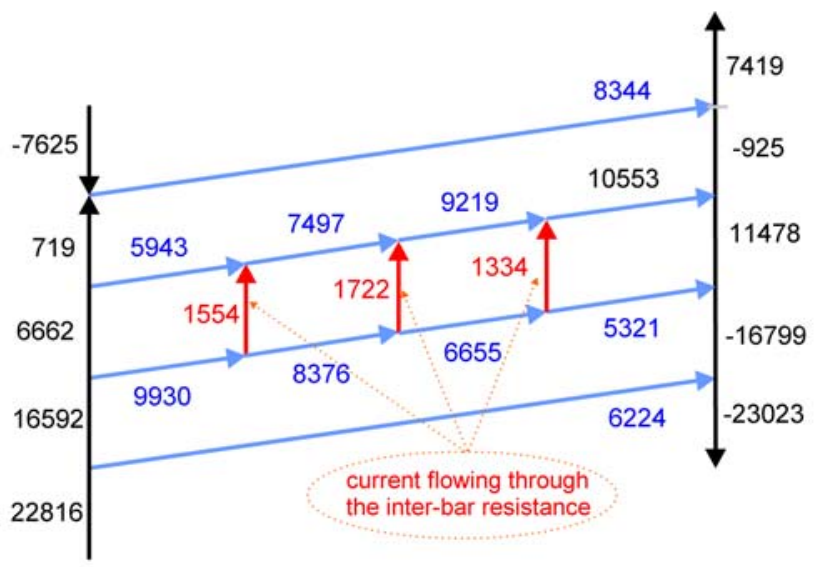

Figure 17 - Current distribution in the rotor grid at a given time with two transversal resistances.

The fundamental components of the currents in the bar segments surrounding the three transversal resistances is shown in Fig. 18. This figure shows now that the current in all bar segments surrounding the inter-bar resistances are affected by their presence. The currents in bar segments $\mathrm{E}$ and $\mathrm{D}$ are visibly decreased while the currents in bar segments $\mathrm{A}, \mathrm{B}, \mathrm{G}$ and $\mathrm{H}$ are increased confirming the previous conclusion.

The overall view of the amplitudes of the fundamental of the inter-bar currents in the cases discussed above is presented in Fig. 19.

It is observed that for only one transversal resistance inserted between rotor bars the amplitude of the fundamental of the inter-bar current is about $2822 \mathrm{~A}$ and is higher than the corresponding current on the same resistance when two (1801 A) or three (1673 A) resistances are inserted. Another observation is that the amplitude of the fundamental component of the inter-bar currents over the two or three resistances cases is not constant. In fact, the amplitude of the inter-bar current is higher for the resistance closer to the middle of the rotor.

The curves of the torque as a function of time without any inter-bar resistance and with 1, 2 and 3 inter-bar resistances are shown in Fig. 20 over one cycle of $60 \mathrm{~Hz}$. It can be observed that the insertion of the inter-bar resistances increased slightly the instantaneous value of the torque. 


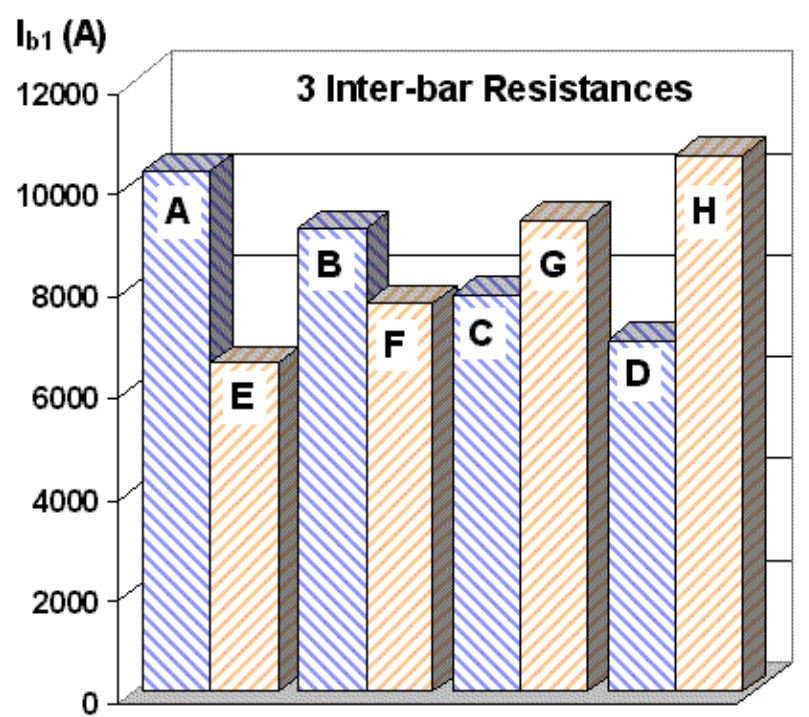

Figure 18 - Amplitude of the fundamental component of the bar currents surrounding inter-bar resistances R1, R2 and R3(refer to Fig. 7 for notation).

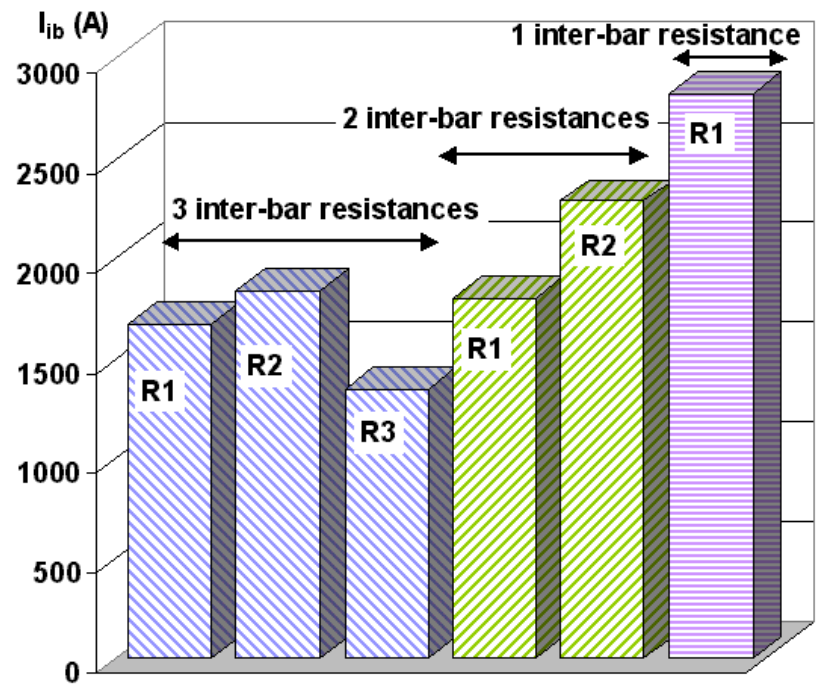

Figure 19 - Amplitude of the fundamental of the inter-bar currents (refer to Fig. 4 for notation)

The Fourier series decomposition of the torque waveforms of Fig. 20 is shown in Fig. 21.

The harmonic decomposition of the torque curves in Fig. 21 shows a $60 \mathrm{~Hz}$ first harmonic and both the stator and rotor slot harmonics, respectively the $17^{\text {th }}$ and $19^{\text {th }}$ and the $21^{\text {st }}$ and $23^{\text {rd }}$. The effect of the existence of inter-bar currents acts differently over the harmonics of torque. Over the first harmonic this effect is significant, reducing its amplitude. Over the continuous component of torque their effect is not perceptible, its calculated value varies as follows:

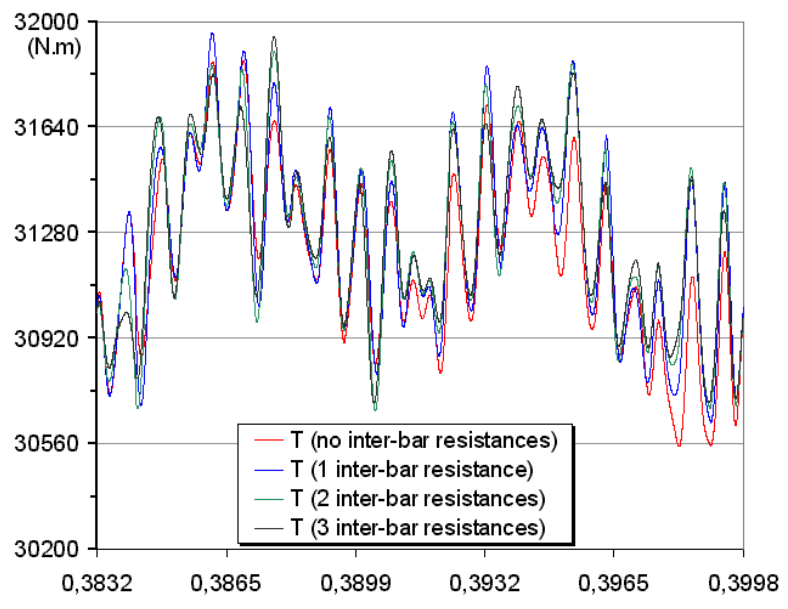

Figure 20 - Waveform of the torque.

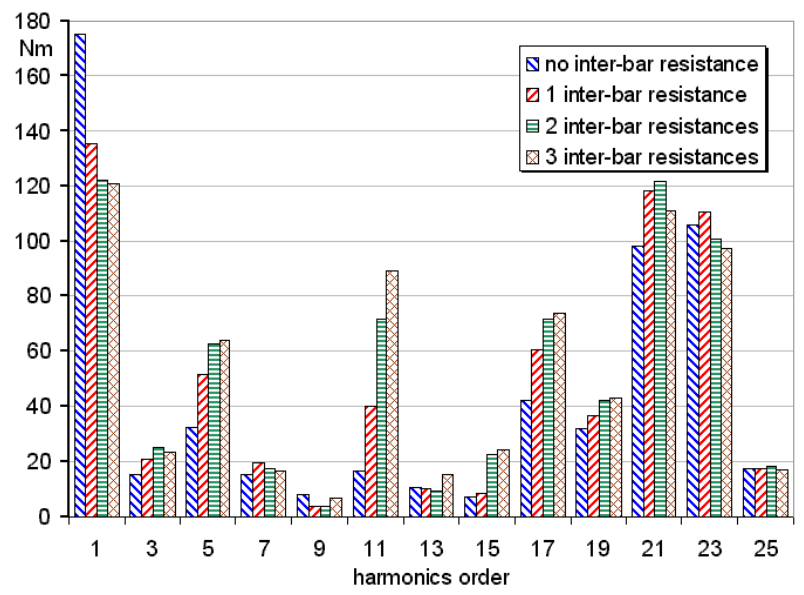

Figure 21 - Decomposition of the torque into a Fourier series.

- no inter-bar resistance $\quad: 31,204 \mathrm{Nm}$

- 1 inter-bar resistance $\quad: 31,263 \mathrm{Nm}$

- 2 inter-bar resistances $: 31,279 \mathrm{Nm}$

- 3 inter-bar resistances $\quad: 31,281 \mathrm{Nm}$

These differences may be attributed to numerical errors.

\section{CONCLUSION}

An analysis of the inter-bar currents circulating in the rotor circuit of a skewed cage induction motor is presented.

The adopted numerical method is based on 2D-Finite Element Method and the Circuits Theory (Independent Current Method) and uses the Multi-Sliced Method to consider the skewing effect. 
The main goal of this work was to contribute for the understanding of the phenomenon of inter-bar currents in the rotor of squirrel-cage induction motors.

The results presented confirm the theoretical results of Odok (1958) concerning the fact that inter-bar currents can circulate in the rotor if there are inter-bar low resistance paths even when the rotor is not skewed conditioned to having non zero ring impedance.

The analysis of three cases with one, two and three inter-bar resistances showed that the skewing makes the rotor asymmetrical in the axial direction. This fact makes the inter-bar currents circulation path be 'displaced' in the direction of the skew. Comparing the figures of rotor currents distribution at a given time without skew and with skew evidences this conclusion. Another important conclusion concerns the motor torque which continuous component is very slightly influenced by the presence of the inter-bar currents. These currents affect only its harmonic components mainly the first one that corresponds to the $60 \mathrm{~Hz}$ mains frequency.

\subsection{ACKNOWLEDGEMENT}

This research was supported in part by WEG Industries from Jaragua do Sul, Brazil.

\section{References}

Glew, C.N. (1997). Stray Load Losses in Induction Motors: A Challenge to Academia. Proc. of the 8th IEE Intl. Cont. on Electrical Machines and Drives, Cambridge, England, pp. 180 -184.

Odok, A. (1958). Stray Load Losses and Stray Torques in Induction Machines. Trans. AIEE, Vol. 77, $\mathrm{n}^{\circ}$ 4, pp. 43-53.

Rao, V.S. and Butler, O.I. (1969). Stray Load Losses of Polyphase Cage Induction Motors with particular reference to the condition of imperfect rotor-bar-iron insulation. Proc. of the IEE, Vol. 116, nº. 5, pp. 737751.

Williamson, S. and Boger, S. (1999). Impact of Inter-Bar Currents on the Performance of the Brushless Doubly Fed Motor. IEEE Trans. Ind. Applicat., Vol. $35, \mathrm{n}^{\circ} 2$, pp. $453-460$.

Ho, S.L., Fu, W.N. and Wong, H.C. (1998). Estimation of Stray Losses of Skewed Rotor Induction Motors Using Coupled 2-D and 3-D Time Stepping Finite Element Methods, IEEE Trans. on Magn., Vol. 34, $\mathrm{n}^{\circ}$ 5, Part 1, pp. $3102-3105$.
Ho, S.L., Li, H.L. and Fu, W.N. (1999). Inclusion of Interbar Currents in a Network-Field Coupled TimeStepping Finite-Element Model of Skewed Rotor Induction Motor. IEEE Trans. Magn., vol. 35, pp. $4218-4225$.

Boite, R. and Neirynck, J. (1996). Théorie des Réseaux de Kirchhoff - Traité d'Electricité, 328 pages, Vol. IV, Presses Polytechniques Romandes, Lausanne, Switzerland.

da Silva, C.A., Carlson, R., Sadowski, N., Lefevre, Y. and Lajoie-Mazenc, M. (2000). A New Method to Calculate the Inter-bar Currents in Induction Motors - Part I -Methodology, Proc. of the 9th International IGTE Symposium on Numerical Field Calculation in Electrical Engineering - IGTE 2000, Graz, Austria, pp. 436-439.

da Silva, C.A., Carlson, R., Sadowski, N., Lefevre, Y. and Lajoie-Mazenc, M. (2000). A New Method to Calculate the Inter-bar Currents in Induction Motors - Part II - Results : The Skewing Effect, Proc. of the 9th International IGTE Symposium on Numerical Field Calculation in Electrical Engineering - IGTE 2000, Graz, Austria, pp. 245247. 